\title{
Application of quality by design approach in RP-HPLC method development for simultaneous estimation of saxagliptin and dapagliflozin in tablet dosage form
}

\author{
Aruna Gundala ${ }^{*}$, KVSRG Prasad², Bharathi Koganti ${ }^{\circledR 2}$ \\ ${ }^{1}$ Department of Quality Assurance, Krishna Teja Pharmacy College, Tirupati, Andhra Pradesh, India, ${ }^{2}$ Institute of \\ Pharmaceutical Technology, Sri Padmavati Mahila Visvavidyalayam (Women's University), Tirupati, Andhra Pradesh, India.
}

\begin{abstract}
A simple, sensitive, precise, accurate and robust high performance liquid chromatographic method has been developed for simultaneous estimation of saxagliptin (SAXA) and dapagliflozin (DAPA) in pharmaceutical formulation. Design of experiments (DoE) was applied for multivariate optimization of the experimental conditions of RP-HPLC method. Risk assessment was performed to identify the critical method parameters. Three independent factors; mobile phase composition, flow rate and column temperature were used to design mathematical models. Central composite design (CCD) was used to study the response surface methodology and to study in depth the effects of these independent factors. Desirability function was used to simultaneously optimize the retention time and resolution of SAXA and DAPA. The optimized and predicted data from contour diagram consisted of acetonitrile and ortho phosphoric acid $(0.1 \%)$ in the ratio of $50: 50$ respectively, at a flow rate of $0.98 \mathrm{ml} / \mathrm{min}$ and column temperature $31.4{ }^{\circ} \mathrm{C}$. Using these optimum conditions baseline separation of both drugs with good resolution and run time of less than 6 min were achieved. The optimized assay conditions were validated according to ICH guidelines. Hence, the results clearly showed that Quality by design approach could be successfully applied to optimize RP-HPLC method for simultaneous estimation of SAXA and DAPA.
\end{abstract}

Keywords: Saxagliptin/pharmacology. Dapagliflozin/pharmacology. Quality by Design. RP-HPLC/ methods. Optimization/methods. Chromatography, High Pressure Liquid/ methods. Dosage Forms. Tablets/administration \& dosage.

\section{INTRODUCTION}

Saxagliptin (SAXA), chemically, known as $(1 \mathrm{~s}, 3 \mathrm{~s}, 5 \mathrm{~s})-2-[(2 \mathrm{~s})-2-$ a mino-2-(3-hydroxyltricyclo[3.3.1.1]dec-1-yl)acetyl]-2-azabicyclo[3.1.0] hexane-3-carbonitrile (Figure 1), is a potent, selective, long-acting, and reversible inhibitor of the enzyme dipeptidyl peptidase 4 (DPP-4) used for treatment of type 2 diabetes mellitus. It is used as monotherapy or in combination with other drugs (Scheeren et al., 2015; Hanan et al., 2017).

Dapagliflozin (DAPA) is chemically described as (1s)-1,5-anhydro-1-C-[4-chloro-3-[(4-ethoxy phenyl) methyl]phenyl]-D-glucitol (Figure 2) (Meira et al., 2017). It belongs to a new class of oral antidiabetic drugs called sodium glucose cotransporter 2 (SGLT2) inhibitors.

\footnotetext{
Correspondance: A. Gundala. Department of Quality Assurance, Krishna Teja Pharmacy College, Tirupathi, A.P, India. Tel: +91-9704624158. E-mail: garuna.mpharm@gmail.com
}

These sodium glucose cotransporters are responsible for glucose reabsorption in the kidney (Manasa et al., 2014). DAPA is a first generation, selective SGLT inhibitor that blocks glucose transport with 100 - fold selectivity for SGLT2 over SGLT1 (Jani, Shah, Kapupara, 2015a). The US FDA has approved a once-daily dose of Qtern $(10 \mathrm{mg}$ Dapagliflozin and $5 \mathrm{mg}$ Saxagliptin) for the treatment of type-2 diabetes (Madhavi, Prameela Rani, 2017).

An extensive literature survey has revealed that there is no reverse phase high performance liquid chromatographic (RP HPLC) method available for individual or simultaneous estimation of SAXA and DAPA in bulk, or pharmaceutical dosage forms use an experimental design approach. A few analytical methods were reported in the literature for the determination of SAXA alone. Stability indicating RP HPLC and RP-LC-PDA methods for determination of SAXA in pharmaceutical dosages were developed (Scheeren et al., 2015; Konari, Jacob, 2015). SAXA was estimated, 
with other antidiabetic drugs like vildagliptin, using spectrophotometric and spectrofluorimetric methods from bulk and pharmaceutical dosage forms (Marwa, 2013) and also with metformin hydrochloride, using the RP column liquid chromatographic method in binary mixtures (Mohammad, Ehab, Marwa, 2012), The HPLC method is used in active drug and pharmaceutical dosage forms (Hanan et al., 2017) and stability indicating RP HPLC method for the determination of saxagliptin and metformin in bulk and pharmaceutical product (Ramesh, Senthil Kumar, 2016). Some analytical procedures have been reported for quantitative determination of DAPA alone by UV spectrophotometry only in API (Manasa et al., 2014) and the RP HPLC method in bulk and tablet dosage forms (Subrata, Vipul, 2017). Simultaneous estimation of DAPA and metformin hydrochloride has also been developed using the UV spectrophotometric method and first derivative photometric method in a synthetic mixture (Jani, Shah, Kapupara, 2015b). Literature has depicted very critical care and typical reports of RP HPLC for simultaneous estimation of SAXA and DAPA in bulk and tablet form namely, a new stability indicating by the RP HPLC method (Vinutha, Chowdary, Prasad, 2017) and precise UPLC (Madhavi, Prameela Rani, 2017). These methods did not describe the design space as per recent FDA guidelines. The use of 'Quality by Design' (QbD) or 'Design of Experiments' (DoE) is recommended to achieve robustness during analytical method validation by statistical quality control monitoring and by the study of factors that negatively affect quality in pharmaceutical analysis (Ganorkar, Dhumal, Shirkhedkar, 2017).

The traditional approach of method development is comprised of trial and error and by varying one factor at a time (Yadav et al., 2016). This approach often encounters difficulties in optimizing robust chromatographic conditions due to various factors, like limited availability of the chromatographic column, solvents, chemicals, and critical physicochemical properties of the analyte. Recently the FDA has approved few new drug applications (NDA) that have applied the QbD approach to analytical techniques, like HPLC and UV Spectrophotometry, in which regulatory flexibility has been granted for movement within the defined method operable design region (MODR) (Peraman et al., 2015). Since its implementation by the FDA, QbD has been an integral part of the pharmaceutical product development process, impacting its robustness (Awotwe-Otoo et al., 2012). A modern QbD based treatment of the robustness of the HPLC method requires the assessment of all factors which most strongly influence the results of the method. The experimental verification of many factors simultaneously is impractical and associated with difficulties and more expense. To overcome the challenge and reduce the experimental workload, a thorough understanding of the response of the system quality to system parameters that leads ultimately to the establishment of design space for the method is important (Awotwe-Otoo et al., 2012; Monks et al., 2012).

Hence, our quest for developing a simple, rapid, precise, robust RP HPLC method for analysis of SAXA and DAPA, assisted with DoE, was developed and central composite design (CCD) for evaluation of robustness of developed method, followed by graphical interpretation of data by response surface methodology (RSM).

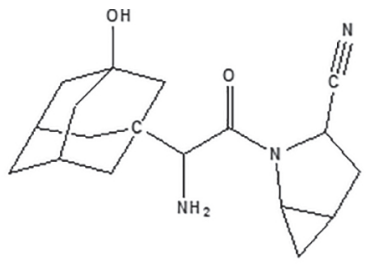

FIGURE 1 - Chemical structure of saxagliptin.

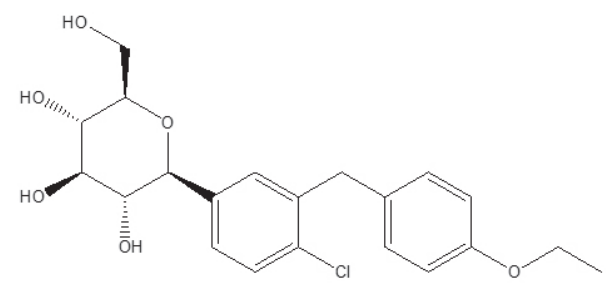

FIGURE 2 - Chemical structure of dapagliflozin.

\section{MATERIAL AND METHODS}

\section{Material}

Pure SAXA and DAPA samples were obtained from Spectrum Pharma Research Solutions, Hyderabad, India as a gift. Acetonitrile was of HPLC grade and orthophosphoric acid was of analytical-reagent grade supplied by Merck (Mumbai, India). HPLC grade water was obtained following distillation in glass and passage through a Milli-Q Academic system (Millipore, Bangalore, India) and was used to prepare all solutions. Qtern tablet formulation was purchased from local market. This formulation had a label claim of $5 \mathrm{mg}$ of SAXA and $10 \mathrm{mg}$ of DAPA each.

\section{Instrumentation}

A Waters HPLC instrument- LC-20AD (Japan) equipped with rheodyne 7725 injection valve with a 
$20 \mu \mathrm{L}$ loop volume and binary gradient pump was used. The system also included a PDA (Shimadzu, SPD-20A) detector operated at a wavelength of $210 \mathrm{~nm}$. Data were acquired and processed by using empower 2 software. Chromatographic separation was performed using Discovery C18 column ( $250 \mathrm{~mm}, 4.6 \mathrm{~mm}$, and $5 \mu \mathrm{m})$.

\section{Software}

Experimental design (CCD), desirability function, and data analysis calculations were performed by using Design-Expert version 10.0.3.1.

\section{Methods}

\section{Diluent}

Buffer: Acetonitrile in the ratio of 50:50 was used as diluent.

\section{Preparation of Buffer: (0.1\% OPA)}

$1 \mathrm{~mL}$ of orthophosphoric acid was accurately transferred into a $1000 \mathrm{~mL}$ volumetric flask and about $900 \mathrm{~mL}$ of milli-Q water added. The solution was degased by sonication and then brought up to the volume $(1000 \mathrm{~mL})$ with water.

\section{Preparation of standard stock solution}

About $5 \mathrm{mg}$ of SAXA and $10 \mathrm{mg}$ of DAPA were accurately weighed and transferred in to a $10 \mathrm{~mL}$ clean, dry volumetric flask. The contents of the flask were dissolved in diluent, sonicated for $30 \mathrm{~min}$, and made up to the final $10 \mathrm{~mL}$ volume with diluent. From the above stock solutions, $1 \mathrm{~mL}$ was pipetted out into another $10 \mathrm{~mL}$ volumetric flask and then made up to the $10 \mathrm{~mL}$ volume with diluent.

\section{Sample preparation}

10 tablets were weighed and crushed. From that, a powder equivalent to $5 \mathrm{mg}$ and $10 \mathrm{mg}$ of SAXA and DAPA was weighed accurately and transferred into a $10 \mathrm{~mL}$ clean dry volumetric flask. The contents of the flask were dissolved in diluent, sonicated for $30 \mathrm{~min}$, and made up to the final volume with diluent and labeled as Sample stock solution. Sample stock solution was filtered by PVDF 0.45 um filters. $1 \mathrm{~mL}$ of filtered sample stock solution was transferred to $10 \mathrm{~mL}$ volumetric flask and made up to the volume $(10 \mathrm{~mL})$ with diluent.

\section{Chromatographic procedure}

Chromatographic separations were carried out on a Discovery C18 column ( $250 \mathrm{~mm}, 4.6 \mathrm{~mm}$, and $5 \mu \mathrm{m})$. A mixture of acetonitrile and $0.1 \%$ orthophosphoric acid (50:50) was used as the mobile phase. Wavelength of $210 \mathrm{~nm}$ was used for detection, at which both drugs gave good response.

\section{Software aided method optimization}

Literature revealed that some design methodologies were presented to assess the robustness of method (Ganorkar, Dhumal, Shirkhedkar, 2017). They applied in the circumstances of optimizing separation techniques during screening, testing of robustness and also in the context of optimizing formulation, products, or method. Here in the present work, the important chromatographic factors were selected, based on preliminary experiments and prior knowledge from the literature. A good choice among the screening design in the testing of few factors (three or less) for robustness, may be CCD because of its efficiency, with respect to number of runs required (Petkovska, Cornett, Dimitrovska, 2008).Various factors were considered for method development, including volume of organic solvents in the mobile phase, buffer, flow rate, and column temperature (Dawud, Shakya, 2014). Thus, CCD was employed to evaluate the effects of three independent chromatographic parameters on the three defined key response variables. The design was comprised of 20 experimental runs and helped in screening of factors by evaluating their main effect to get outcomes of the study. A $3^{2}$ factorial design indicated that there were two levels and three factors were involved. The two levels were low (-1) and high $(+1)$, whereas factors were $\left(\mathrm{X}_{1}\right)$ proportion of organic solvent used in mobile phase $(45 \%$ and $55 \%),\left(\mathrm{X}_{2}\right)$ flow rate of mobile phase $(0.9$ and $1.1 \mathrm{~mL} / \mathrm{min}$ ), and $\left(\mathrm{X}_{3}\right)$ column temperature (28 and $\left.32{ }^{\circ} \mathrm{C}\right)$. The retention time of SAXA $\left(\mathrm{Y}_{1}\right)$, retention time of DAPA $\left(\mathrm{Y}_{2}\right)$, and resolution $\left(\mathrm{Y}_{3}\right)$ were used as responses in experimental design and were shown in Table I. The resulting data were fitted into Design-Expert version 10.0.3.1. Response surface quadratic methodology was a suitable method and was used to explore, to investigate behavior of the response around optimized values of the factors, and to attain the best system performance (Ficarra et al., 2002). Analysis of variance (ANOVA) was applied to examine the significance of the model. From this optimized method, conditions were selected and subjected to verification for method performance, like accuracy, precision (less than $2 \% \mathrm{RSD}$ ), and robustness as targeted 
response (Peraman et al., 2015). Twenty experiments were constructed using the conditions and observed responses are described in Table II.

\section{Method validation}

The optimized chromatographic method was validated according to the International Conference on Harmonization (ICH) (2005) Q2R(1) guidelines for system suitability, linearity, limit of detection, limit of quantitation, precision, accuracy, specificity, and robustness.

\section{System suitability test}

According to United States Pharmacopoeia (USP), system suitability tests are integral part of liquid chromatographic methods. (Ganorkar, Dhumal,

TABLE I - Experimental plan of CCD showing factors with levels

\begin{tabular}{lccc}
\hline \multirow{2}{*}{ Factors } & \multirow{2}{*}{ Code } & Low (-1) & High (+1) \\
\cline { 3 - 4 } & & 45 & 55 \\
Proportion of organic solvent used in mobile phase & $\mathrm{X}_{1}$ & 0.9 & 1.1 \\
Flow rate of mobile phase $(\mathrm{mL} / \mathrm{min})$ & $\mathrm{X}_{2}$ & 28 & 32 \\
Column temperature & $\mathrm{X}_{3}$ & & - \\
\hline Responses & & - & - \\
\hline Retention time of SAXA & $\mathrm{Y}_{1}$ & - & - \\
Retention time of DAPA & $\mathrm{Y}_{2}$ & - & - \\
Resolution & $\mathrm{Y}_{3}$ & & \\
\hline
\end{tabular}

TABLE II - Coded values for factor level and observed responses in CCD for 20 analytical trials

\begin{tabular}{cccccccc}
\hline $\begin{array}{c}\text { Experiment } \\
\text { (Run) }\end{array}$ & Type & $\mathbf{X}_{\mathbf{1}}$ & $\mathbf{X}_{\mathbf{2}}$ & $\mathbf{X}_{\mathbf{3}}$ & $\mathbf{Y}_{\mathbf{1}}$ & $\mathbf{Y}_{\mathbf{2}}$ & $\mathbf{Y}_{\mathbf{3}}$ \\
\hline 1 & Factorial & 45 & 0.9 & 28 & 3.204 & 3.876 & 3.5 \\
2 & Axial & 41.591 & 1 & 30 & 2.889 & 3.575 & 3.7 \\
3 & Factorial & 45 & 1.1 & 32 & 2.582 & 3.17 & 3.8 \\
4 & Axial & 58.409 & 1 & 30 & 2.687 & 3.297 & 3.8 \\
5 & Center & 50 & 1 & 30 & 2.771 & 3.405 & 3.6 \\
6 & Center & 50 & 1 & 30 & 2.772 & 3.407 & 3.6 \\
7 & Center & 50 & 1 & 30 & 2.771 & 3.406 & 3.6 \\
8 & Axial & 50 & 1 & 26.6364 & 2.769 & 3.746 & 4.8 \\
9 & Center & 50 & 1 & 30 & 2.772 & 3.407 & 3.6 \\
10 & Factorial & 55 & 1.1 & 32 & 2.491 & 3.05 & 4.2 \\
11 & Axial & 50 & 1.16818 & 30 & 2.395 & 2.948 & 3.7 \\
12 & Center & 50 & 1 & 30 & 2.77 & 3.406 & 3.6 \\
13 & Factorial & 55 & 1.1 & 28 & 2.486 & 3.157 & 3.8 \\
14 & Factorial & 55 & 0.9 & 28 & 3.046 & 3.833 & 4.1 \\
15 & Center & 50 & 1 & 30 & 2.771 & 3.407 & 3.6 \\
16 & Factorial & 45 & 1.1 & 28 & 2.615 & 3.517 & 4.7 \\
17 & Axial & 50 & 0.831821 & 30 & 3.33 & 4.107 & 3.8 \\
18 & Factorial & 55 & 0.9 & 32 & 3.029 & 3.716 & 4.3 \\
19 & Axial & 50 & 1 & 33.3636 & 2.792 & 3.42 & 4.3 \\
20 & Factorial & 45 & 0.9 & 32 & 3.17 & 3.903 & 4.2 \\
\hline
\end{tabular}


Shirkhedkar, 2017). System suitability parameters, like number of theoretical plates, resolution, and tailing factor were evaluated by injecting six replicates of standard solutions containing $50 \mu \mathrm{g} / \mathrm{mL}$ of SAX and $100 \mu \mathrm{g} / \mathrm{mL}$ of DAPA before the sample analysis. In all cases, the percent relative standard deviation should be $<2.0 \%$. The acceptance criteria for standards in system suitability were set in each chromatogram (Thakur, Kaur, Sharma, 2017; Agrawal, Desai, Jani, 2016).

\section{Linearity}

Linearity of the developed method was established at six levels over the range of $12.5-75 \mu \mathrm{g} / \mathrm{mL}$ for SAXA and $25-150 \mu \mathrm{g} / \mathrm{mL}$ for DAPA. Each linearity solution of respective sample concentrations was injected in triplicate. The calibration curve was constructed by plotting the peak area against the concentration, using linear regression analysis.

\section{Accuracy and precision}

Accuracy was carried out by adding a known amount of standard to the tablet solution for each drug at 50, 100, and $150 \%$ levels in triplicate, and samples were analyzed by the optimized method. Percentage recovery was then calculated for both drugs. The mean recovery of the target concentrations was set to $100 \pm 2 \%$ for acceptance (Patel et al., 2017). Precision of the optimized method was determined by studying the intermediate precision and repeatability. Intermediate precision expresses withinlaboratories variations: different days, different analysts, different equipment, etc. Intermediate precision is also known as inter-assay precision. Repeatability expresses the precision under the same operating conditions over a short interval of time (Pradipbhai et al., 2017). Six homogenous samples of SAXA and DAPA were assayed to assess the method precision (Yadav et al., 2016; Thakur, Kaur, Sharma, 2017).

\section{Limit of detection (LOD) and limit of quantitation (LOQ)}

LOD and LOQ of SAXA and DAPA were evaluated using the standard deviation method. LOD was defined as $3.3 \mathrm{\sigma} / \mathrm{S}$ and LOQ as $10 \sigma / \mathrm{S}$ based on standard deviation of the response $(\sigma)$ and slope of the calibration curve $(S)$.

\section{Robustness}

The robustness of the method refers to its ability to remain unaffected by small and deliberate variations in method parameters. The robustness of the optimized method was investigated by injecting the system suitability solution with minute deliberate changes in the chromatographic parameters, flow rate (0.97-0.99 $\mathrm{mL} / \mathrm{min})$, proportion of solvent in mobile phase (45:55) and temperature of the column $\left(30.04-32.24^{\circ} \mathrm{C}\right)$. It was measured on the basis of percent relative standard deviation.

\section{RESULTS AND DISCUSSION}

\section{Preliminary studies and factor selection}

There were only a few works reported on implementation of QbD in analytical method development (Peraman et al., 2015).

In search of a simple, robust, and cost effective RP-HPLC method for estimation of SAXA and DAPA in tablet formulation, a preliminary study was initially carried out. The important chromatographic factors were selected, based on preliminary experiments and prior reports from the literature. Such investigations to select the factor levels for screening and optimization studies revealed that mobile phase conditions needed to be optimized so that both SAXA and DAPA would be separated in a short run time. Mobile phase composition of $0.1 \%$ OPA buffer and acetonitrile was found to be more suitable for the simultaneous estimation of both the drugs and the volume of acetonitrile resulted in a large change in retention time. Hence, it is considered as one of the critical parameters for method development.

For further study, different reverse phase columns were tried but finally satisfactory separation was obtained on a Discovery C18 column. From Ishikawa diagram and Pareto ranking analysis, preliminary experiments were conducted and the critical parameters selected for further study, were flow rate and column temperature which were found to have the most influential effect on system suitability parameters. Studies carried out with protamine sulphate also resulted in selection of similar critical parameters (Awotwe-Otoo et al., 2012).

\section{QbD assisted method development}

CCD design was employed in the present analytical method optimization study. It is an efficient and comprehensive experimental design based on systematic scouting of three key components of the RP-HPLC method (volume of organic phase, flow rate, and column temperature) is depicted. 
For the RP-HPLC method, a multivariate approach DoE with CCD was applied to study the simultaneous variations of the factors on considered responses, such as retention time of SAXA (Y1), retention time of DAPA (Y2), and resolution (Y3) to test method robustness. Based on the effects of three factors on responses and evaluation of these results, it was feasible to elaborate mathematical models that had been endeavored to find out the relationship between the factors and the responses of interest studied. We observed that the best fitted model for CCD was the response surface quadratic model. The model was also validated by ANOVA using Design Expert software. The predicted R- squared values of retention time of SAXA $\left(\mathrm{Y}_{1}\right)$ and DAPA $\left(\mathrm{Y}_{2}\right)$ were in reasonable agreement with adjusted $\mathrm{R}$ - squared values i.e., the difference is less than 0.2 , as reported by other authors (Pradipbhai et al., 2017). A negative predicted R-squared value for resolution $\left(\mathrm{Y}_{3}\right)$ implies that the overall mean may be a better predictor of the response than the current model. Adequate precision, measures the signal to noise ratio. A ratio of greater than 4 is desirable and the obtained responses for the $\mathrm{Y}_{1}, \mathrm{Y}_{2}$, and $\mathrm{Y}_{3}$ were $96.445,29.953$, and 6.118 , respectively, which indicates an adequate precision. This quadratic model can be used to navigate the design space. Model F-value of responses for retention time of $\operatorname{SAXA}\left(\mathrm{Y}_{1}\right)$, retention time of DAPA $\left(\mathrm{Y}_{2}\right)$, and resolution $\left(\mathrm{Y}_{3}\right)$ were $666.4,70.44$, and 4.45 , which implies the model is significant. There is only a $0.01 \%$ chance, in the case of $\mathrm{Y}_{1}$ and $\mathrm{Y} 2$, while a $1.44 \%$ chance for resolution $\left(\mathrm{Y}_{3}\right)$ than an F-value, indicating that this could occur due to noise. Hence, the values of significant responses showed $p$ value $<0.05$, suggesting that the model terms are significant. The low standard deviation and high adjusted $\mathrm{R}$-square value indicates a good relationship between experimental data and those of fitted models.

The equations in terms of coded factors can be used to make predictions about the response for given levels of each factor. This equation is useful for identifying the relative impact of the factors by comparing the factor coefficient. Final equations for $Y_{1}, Y_{2}$ and $Y_{3}$ are:

$\operatorname{SAXA}\left(\mathrm{Y}_{1}\right)=+2.77-0.063 \mathrm{X}_{1}-0.28 \mathrm{X}_{2}-2.95 \mathrm{X}_{3}+9.87 \mathrm{X}_{1} \mathrm{X}_{2}$ $+6.87 \mathrm{X}_{1} \mathrm{X}_{3}+2.87 \mathrm{X}_{2} \mathrm{X}_{3}+9.15 \mathrm{X}_{1}^{2}+0.03 \mathrm{X}_{2}^{2}+6.50 \mathrm{X}_{3}^{2}$;

DAPA: $\left(\mathrm{Y}_{2}\right)=+3.41-0.08 \mathrm{X}_{1}-0.32 \mathrm{X}_{2}-0.08 \mathrm{X}_{3}-0.03 \mathrm{X}_{1} \mathrm{X}_{2}+$ $0.01 \mathrm{X}_{1} \mathrm{X}_{3}-0.04 \mathrm{X}_{2} \mathrm{X}_{3}+0.01 \mathrm{X}_{1}^{2}+0.044 \mathrm{X}_{1}^{2}+0.06 \mathrm{X}_{3}^{2}$;

Resolution: $\left(\mathrm{Y}_{3}\right)=+3.60+0.02 \mathrm{X}_{1}+0.01 \mathrm{X}_{2}-0.03 \mathrm{X}_{3}$ $0.15 \mathrm{X}_{1} \mathrm{X}_{2}+0.10 \mathrm{X}_{1} \mathrm{X}_{3}-0.17 \mathrm{X}_{2} \mathrm{X}_{3}+0.06 \mathrm{X}_{1}^{2}+0.06 \mathrm{X}_{2}^{2}+$ $0.34 \mathrm{X}_{3}^{2}$.
As per the values of coefficient from the above equations and their signs, it is clear that factors, such as mobile phase composition $\left(\mathrm{X}_{1}\right)$, flow rate $\left(\mathrm{X}_{2}\right)$, and column temperature $\left(\mathrm{X}_{3}\right)$, had a negative effect on retention time of SAXA and DAPA, $Y_{1}$ and $Y_{2}$. The column temperature $\left(\mathrm{X}_{3}\right)$ had a negative effect on resolution $\left(\mathrm{Y}_{3}\right)$, whereas mobile phase $\left(\mathrm{X}_{1}\right)$ and flow rate $\left(\mathrm{X}_{2}\right)$ had positive effects. Interactions of $X_{1}$ and $X_{2}$ had a positive effect on $Y_{1}$ and $\mathrm{Y}_{2}$ and a negative effect on $\mathrm{Y}_{3} ; \mathrm{X}_{2}$ and $\mathrm{X}_{3}$ had a positive effect on $\mathrm{Y}_{1}$ and a negative effect on $\mathrm{Y}_{2}$ and $\mathrm{Y}_{3} ; \mathrm{X}_{1}$ and $\mathrm{X}_{3}$ had a positive effect on $Y_{1}$ and $Y_{2}$ and a negative effect on $\mathrm{Y}_{3}$. The squares of factors, $\mathrm{X}_{1}{ }^{2}, \mathrm{X}_{2}^{2}$, and $\mathrm{X}_{3}^{2}$, had positive effects on all chromatographic responses.

Response surface and contour plots were analyzed to visualize the effect of the factors and their interactions on the responses (Awotwe-Otoo et al., 2012). The contour plots showed curvature, displaying a nonlinear effect of factors on responses. Figures 3 and 4 showed 2D (A) and $3 \mathrm{D}$ (B) contour plots displaying the effect of mobile phase ratio $\left(\mathrm{X}_{1}\right)$ and flow rate $\left(\mathrm{X}_{2}\right)$ on retention time of SAXA $\left(\mathrm{Y}_{1}\right)$ and DAPA $\left(\mathrm{Y}_{2}\right)$. A curvilinear increasing trend was observed for the mobile phase ratio $\left(\mathrm{X}_{1}\right)$ and flow rate $\left(\mathrm{X}_{2}\right)$, which showed higher resolution time of $\operatorname{SAXA}\left(\mathrm{Y}_{1}\right)$, as well as DAPA $\left(\mathrm{Y}_{2}\right)$ at lower levels. Therefore, lower levels of $\mathrm{X}_{1}$ and $\mathrm{X}_{2}$ were recommended to achieve high retention time of SAXA $\left(\mathrm{Y}_{1}\right)$ and DAPA $\left(\mathrm{Y}_{2}\right)$. The study of 3D and 2D contour plots presented in Figure 5 showed curvature effects of the mobile phase ratio $\left(\mathrm{X}_{1}\right)$ and flow rate $\left(\mathrm{X}_{2}\right)$ on resolution. An increasing curvature trend was observed for both $\mathrm{X}_{1}$ and $\mathrm{X}_{2}$, which showed higher resolution at higher levels. Therefore, optimized levels of $X_{1}$ and $X_{2}$ were recommended to achieve resolution.

A composite desirability was applied to obtain an optimum set of conditions based on the specified goals and boundaries for each response. The desirability function " $R$ ", equal to unity, demonstrated the achievement of desired goals in the constraints set and the whole experimental area was explored for the compositions (Costa, Lourenço, Pereira, 2011), where in constraints set were met to the maximum i.e., unity, as shown in Figure 6 . The optimum values of chromatographic conditions of RP-HPLC were selected as mobile phase $\left(\mathrm{X}_{1}\right)$ buffer and acetonitrile $50: 50$, flow rate $(0.96 \mathrm{~mL} / \mathrm{min})$, and column temperature $31.14{ }^{\circ} \mathrm{C}$ which resulted in retention time of SAXA $\left(\mathrm{Y}_{1}\right) 2.79 \pm 0.0162$, retention time of DAPA $\left(\mathrm{Y}_{2}\right) 3.45 \pm 0.013$, and resolution (Y1) $3.7 \pm 0.002 \mathrm{~min}$, respectively, as shown in Figure 7.

\section{Method validation}

According to the USP, system suitability tests are 


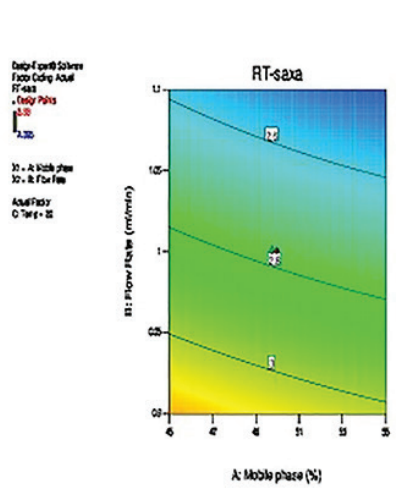

(A)

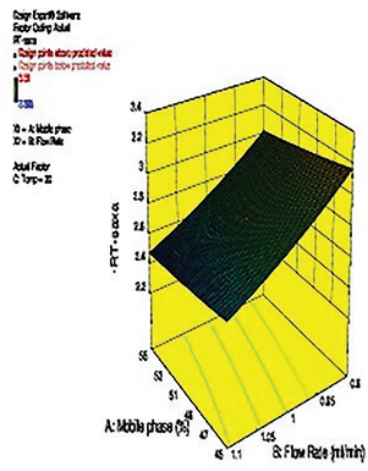

(B)
FIGURE 3 - 2D (A) and 3D (B) contour plots showing the effect of mobile phase ratio $\left(\mathrm{X}_{1}\right)$ and flow rate $\left(\mathrm{X}_{2}\right)$ on retention time of SAXA $\left(\mathrm{Y}_{1}\right)$.

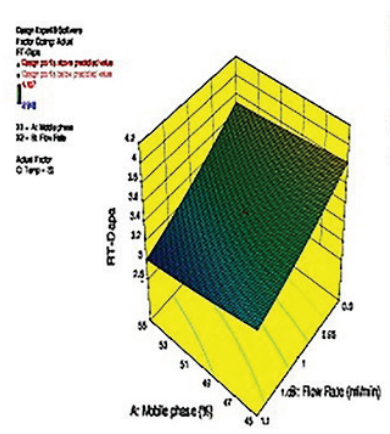

(A)
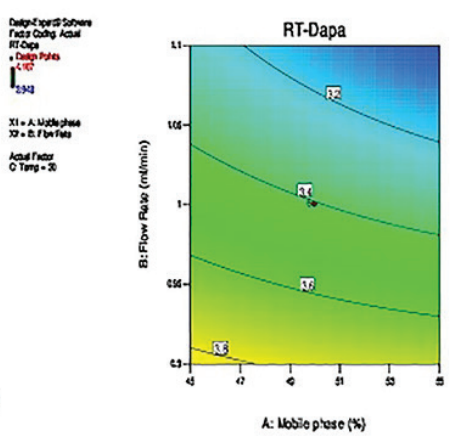

(B)
FIGURE 4 - 2D (A) and 3D (B) contour plots showing the effect of mobile phase ratio $\left(\mathrm{X}_{1}\right)$ and flow rate $\left(\mathrm{X}_{2}\right)$ on retention time of DAPA $\left(\mathrm{Y}_{2}\right)$.

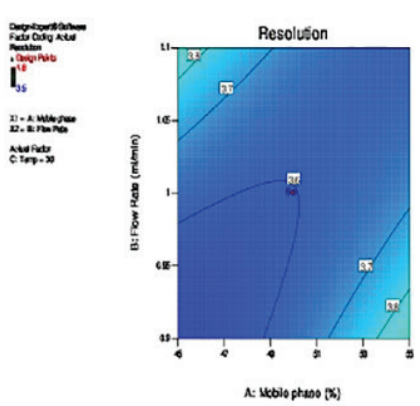

(A)

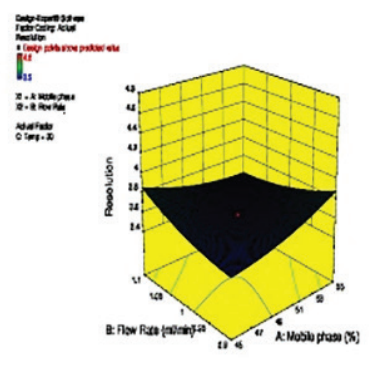

(B)
FIGURE 5 - 2D (A) and 3D (B) contour plots showing the effect of mobile phase ratio $\left(\mathrm{X}_{1}\right)$ and flow rate $\left(\mathrm{X}_{2}\right)$ on resolution $\left(\mathrm{Y}_{3}\right)$.

an integral part of liquid chromatographic methods. The column efficiency, as determined from number of theoretical plates for both the drugs, was found to be more than 4000 , resolution was 3.4, and tailing was found to be less than

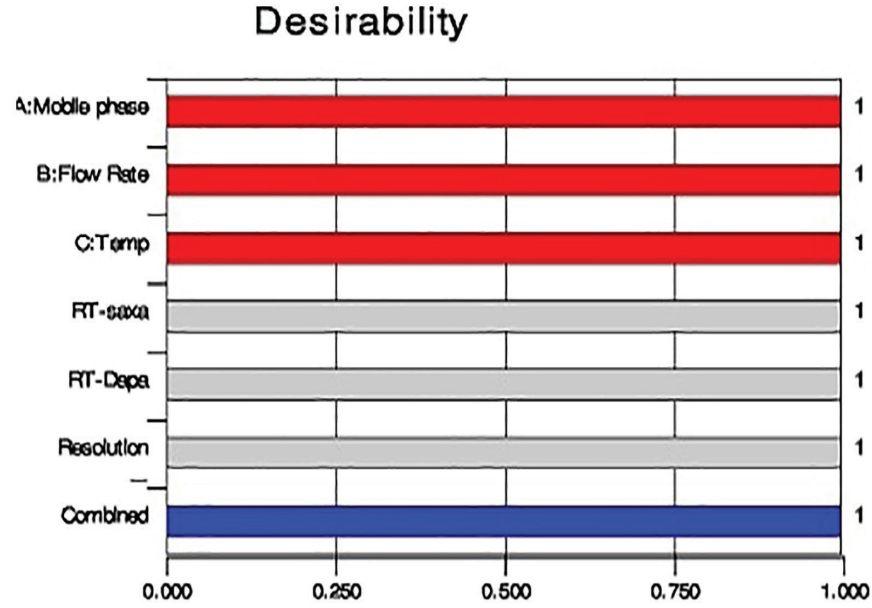

FIGURE 6 - Desirability function representation basis unity=1.

2. The percent relative standard deviation for six replicate injections was found to be 1.2 in the given concentration of $5 \mu \mathrm{g} / \mathrm{mL}$ for SAXA and 0.3 in the given concentration of $10 \mu \mathrm{g} / \mathrm{mL}$ for DAPA, respectively. As \% RSD was found to be less than $2 \%$, it has shown good injection repeatability (Thakur, Kaur, Sharma, 2017). Linearity of the developed method was confirmed by plotting the linearity curve over concentrations ranging from $12.5-75 \mu \mathrm{g} / \mathrm{mL}$ for SAXA and $25-150 \mu \mathrm{g} / \mathrm{mL}$ for DAPA, with a correlation coefficient $\left(\mathrm{r}^{2}=0.999\right)$ for both the drugs, shown in Table IV. The obtained correlation coefficient $\left(\mathrm{r}^{2}=0.999\right)$ demonstrates excellent correlation between peak area and concentration. For the recovery study, different concentrations of samples $(50,100$, and $150 \%)$ of standard concentrations for both drugs were prepared and showed recovery of $99.91 \pm 1.10 \%$ and $98.92 \pm 0.7997 \%$ for SAXA and DAPA, respectively. Data is shown in Table IV, indicating that the developed method has high level of accuracy with \% RSD 0.27 and 0.4 for SAXA and DAPA, respectively. Intermediate precision and repeatability were carried out and the resultant data are given in Table IV. The precision values for both drugs were less than 2\%., indicating that the method was repeatable and precise (Dawud, Shakya, 2014). The LOD and LOQ were found to be 0.13 and $0.39 \mu \mathrm{g} / \mathrm{mL}$, respectively for SAXA, and 0.09 and $0.27 \mu \mathrm{g} / \mathrm{mL}$, respectively for DAPA. The insensitivity of the RP-HPLC method to minor changes in the optimized experimental changes was demonstrated by its robustness to such slight changes. The mobile phase composition, flow rate, and column temperature caused significant effects in the retention time of SAXA and DAPA, as well as resolution.

\section{CONCLUSION}

The present study entails systematic QbD, based 


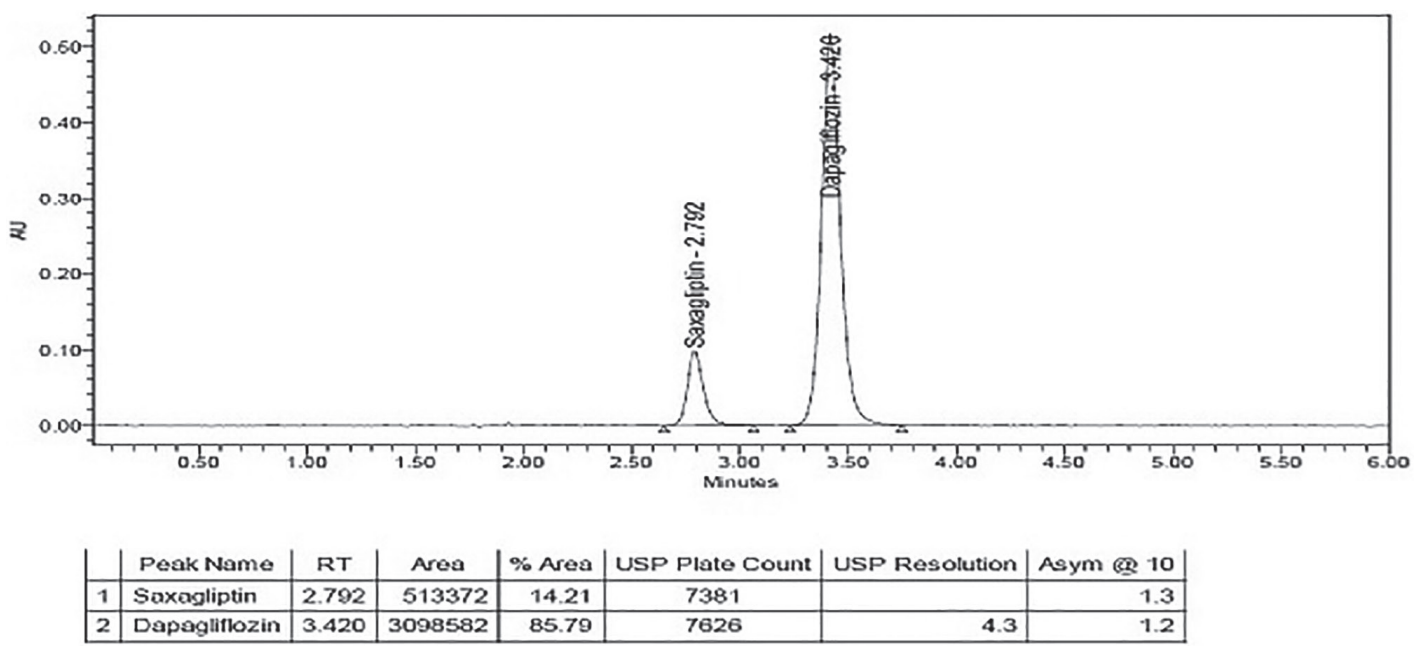

FIGURE 7 - Optimized RP-HPLC chromatogram for SAXA and DAPA at $210 \mathrm{~nm}$

TABLE III - ANOVA regression analysis for models and responses

\begin{tabular}{|c|c|c|c|c|c|c|c|c|c|c|c|c|c|}
\hline Response & Mean & $\mathrm{SD}^{\mathrm{a}}$ & $\% \mathrm{CV}^{\mathrm{b}}$ & $\begin{array}{l}\text { Press } \\
\text { Value }\end{array}$ & $\mathbf{R}^{2 \mathrm{c}}$ & $\begin{array}{c}\text { Adjusted } \\
\qquad \mathbf{R}^{\mathbf{2}}\end{array}$ & $\begin{array}{c}\text { Predicted } \\
\mathbf{R}^{2}\end{array}$ & $\begin{array}{l}\text { Adequate } \\
\text { Precision }\end{array}$ & $\mathbf{S S}^{\mathbf{d}}$ & $d^{\mathrm{e}}$ & $\mathbf{M S}^{\mathrm{f}}$ & $F^{g}$ & $\mathbf{P}$ \\
\hline $\begin{array}{l}\text { Retention time of } \\
\operatorname{SAXA}\left(\mathrm{Y}_{1}\right)\end{array}$ & 2.81 & 0.014 & 0.50 & 0.015 & 0.9983 & 0.9968 & 0.9873 & 96.445 & 1.16 & 9 & 0.13 & 666.4 & 0.0001 \\
\hline $\begin{array}{l}\text { Retention time of } \\
\operatorname{DAPA}\left(\mathrm{Y}_{2)}\right.\end{array}$ & 3.49 & 0.052 & 1.48 & 0.23 & 0.9845 & 0.9705 & 0.8653 & 29.953 & 1.70 & 9 & 0.19 & 70.44 & 0.0001 \\
\hline Resolution $\left(\mathrm{Y}_{3}\right)$ & 3.91 & 0.24 & 6.05 & 4.89 & 0.8003 & 0.6205 & -0.7445 & 6.118 & 2.25 & 9 & 0.25 & 4.45 & 0.0144 \\
\hline
\end{tabular}

${ }^{\mathrm{a}}$ Standard deviation, ${ }^{\mathrm{b}}$ Coefficient of variations, ${ }^{\mathrm{c}}$ Coefficient of Regression, ${ }^{\mathrm{d}}$ Sum of squares, ${ }^{\mathrm{e}}$ Degrees of freedom, ${ }^{\mathrm{f}}$ Mean sum of squares, ${ }^{\mathrm{g}}$ Fischer's ratio

TABLE IV - Validation results for SAXA and DAPA

\begin{tabular}{|c|c|c|c|}
\hline PARAMETERS & & SAXA & DAPA \\
\hline \multicolumn{4}{|c|}{ System suitability parameters } \\
\hline \multirow[t]{2}{*}{ No. of theoretical plates } & Mean $\pm \mathrm{SD}^{*}$ & $4613.66 \pm 96.70$ & $4599 \pm 85.082$ \\
\hline & $\%$ RSD & 2.0 & 1.8 \\
\hline \multirow[t]{2}{*}{ Resolution } & Mean \pm SD & - & $3.266 \pm 0.057$ \\
\hline & $\%$ RSD & - & 1.7 \\
\hline \multirow[t]{2}{*}{ Tailing factor } & Mean $\pm \mathrm{SD}^{*}$ & $1.44 \pm 0.005$ & $1.60 \pm 0.015$ \\
\hline & $\%$ RSD & 0.3 & 0.9 \\
\hline \multicolumn{4}{|l|}{ Linearity } \\
\hline Range( $\mu \mathrm{g} / \mathrm{ml})$ & & $12.5-75$ & $25-150$ \\
\hline Slope & & 11316 & 38865 \\
\hline Intercept & & 3931.8 & 5685.8 \\
\hline Correlation coefficient & & 0.999 & 0.999 \\
\hline \multicolumn{4}{|l|}{ Accuracy } \\
\hline Recovery studies & & $99.91 \pm 1.10$ & $98.92 \pm 0.7997$ \\
\hline$\% \mathrm{RSD}^{* *}$ & & 1.10 & 0.87 \\
\hline \multicolumn{4}{|l|}{ Precision } \\
\hline Repeatability & $\%$ RSD* & 0.27 & 0.4 \\
\hline Intermediate precision & $\%$ RSD* & 0.3 & 0.6 \\
\hline $\operatorname{LOD}(\mu \mathrm{g} / \mathrm{mL})$ & & 0.13 & 0.09 \\
\hline $\operatorname{LOQ}(\mu \mathrm{g} / \mathrm{mL})$ & & 0.39 & 0.27 \\
\hline
\end{tabular}

*Mean of six determinations, **Set of three determinations 
development of a simple, rapid, precise, and cost effective RP-HPLC method for simultaneous estimation of SAXA and DAPA, for the first time. The experimental design describes the scouting of key components, including mobile phase composition, flow rate, and column temperature. The modeling software facilitated better understanding of the factors influencing optimization of the method and separation of SAXA and DAPA. CCD was applied to optimize the resolution as response between SAXA and DAPA in a relatively short time $(6 \mathrm{~min})$. In the optimized model, the acetonitrile and orthophosphoric acid $(0.1 \%)$ in the ratio of 50:50 indicates the suitability for estimation of SAXA and DAPA. The flow rate of the mobile phase was optimized at $0.98 \mathrm{ml} / \mathrm{min}$ and column temperature at $31.4{ }^{\circ} \mathrm{C}$ respectively. The validation study supported the selection of the best conditions by confirming that the method was selective, specific, accurate, linear, precise, and robust. Therefore utilization of the response surface technique provides a better insight for method development and robustness testing. This developed method satisfies the design space concept and is suitable for regulatory submission under regulatory flexibility.

\section{ACKNOWLEDGEMENT}

The author would like to thank to spectrum labs, Hyderabad for providing gift samples of Saxagliptin, Dapaglifazoin.

\section{CONFLICT OF INTEREST STATEMENT}

The authors declare that there are no conflicts of interest regarding this manuscript.

\section{REFERENCES}

Agrawal VP, Desai SS, Jani GK. Development of RP-HPLC for simultaneous determination of brimonidine tartrate and brinzolamide by $\mathrm{QbD}$ approach and its validation. Eurasian $\mathrm{J}$ Anal Chem. 2016;11(2):63-78.

Awotwe-Otoo D, Agarabi C, Faustino PJ, Habib MJ, Lee S, Khan MA, Shah RB. Application of quality by design elements for the development and optimization of an analytical method for protamine sulfate. J Pharm Biomed Anal. 2012;62:61-7.

Costa NR, Lourenço J, Pereira ZL. Desirability function approach: a review and performance evaluation in adverse conditions. Chemom Intell Lab Syst. 2011;107(2):234-44.
Dawud ER, Shakya AK. HPLC-PDA analysis of ACE-inhibitors hydrochlorothiazide and indapamide utilizing design of experiments. Arab. J. Chem. 2014 [In press].

Ficarra R, Calabro ML, Cutroneo P, Tommasini S, Melardi S, Semreen M, et al. Validation of a LC method for the analysis of oxaliplatin in a pharmaceutical formulation using an experimental design. J Pharm Biomed Anal. 2002;29(6):1097103.

Ganorkar SB, Dhumal DM, Shirkhedkar AA. Development and validation of simple RP-HPLC-PDA analytical protocol for zileuton assisted with design of experiments for robustness determination. Arab J Chem. 2017;10(2):273-82.

Hanan AM, Nesrin KR, Sherine SD, Azza AM. Chromatographic methods for the simultaneous determination of binary mixture of saxagliptin $\mathrm{HCl}$ and metformin $\mathrm{HCl}$. Bull Fac Pharm, Cairo Univ. 2017;55(2):311-7.

ICH. Q2 (R1): Guidelines on validation of analytical procedure: text and methodology. 2005. Available from: http://www.ich. org/fileadmin/Public_Web_Site/ICH_Products/Guidelines/ Quality/Q2_R1/Step4/Q2_R1_Guideline.pdf.

Jani BR, Shah KV, Kapupara PP. Development and validation of UV spectroscopic method for simultaneous estimation of dapagliffozin and metformin hydrochloride in synthetic mixture. Int J Res Dev Pharm Life Sci. 2015a;4(3):1569-76.

Jani BR, Shah KV, Kapupara PP. Development and validation of UV spectroscopic first derivative method for simultaneous estimation of dapagliflozin and metformin hydrochloride in Synthetic mixture. J Bioequiv Stud. 2015b; 1(1):1-8.

Konari SN, Jacob JT. Stability indicating validated RP-HPLC technique for the analysis of multicomponent anti-diabetic drug combos in pharmaceutical dosage forms. Karbala Int J Mod Sci. 2015;1(1):39-48.

Madhavi S, Prameela Rani AP. Development and validation of a method for simultaneous determination of dapagliflozin and saxagliptin in a formulation by RP-UPLC. World J Pharma Res. 2017;6(12):904-16.

Manasa S, Dhanalakshmi K, Nagarjuna RG, Kavitha B. Method development and validation of dapagliflozin API by UV Spectroscopy. Int J Pharm Sci Rev Res. 2014;27(1):270-2. 
Marwa SM. Spectrophotometric and spectrofluorimetric methods for the determination of saxagliptin and vildagliptin in bulk and pharmaceutical preparations. Bull Fac Pharm, Cairo Univ. 2013;51(2):139-50.

Meira RZC, Maciel ABi, Murakami FSi, Oliveira PR, Bernardi LS. In vitro dissolution profile of Dapagliflozin: development, method validation and analysis of commercial tablets. Int J Anal Chem. 2017;2017(ID 2951529):1-6.

Mohammad AA, Ehab FE, Marwa AF. Development and validation of a reversed-phase column liquid chromatographic method for simultaneous determination of two novel gliptins in their binary mixtures with Metformin. Chem Eur J. 2012;3(2):152-5.

Monks K, Molnár I, Rieger HJ, Bogáti B, Szabó E. Quality by design: multidimensional exploration of the design space in high performance liquid chromatography method development for better robustness before validation. J Chromatogr A. 2012;1232:218-30.

Patel KG, Patel AT, Shah PA, Gandhi TR. Multivariate optimization for simultaneous determination of aspirin and simvastatin by reverse phase liquid chromatographic method using AQbD approach. Bull Fac Pharm, Cairo Univ. 2017;55(2):293-301.

Peraman R, Bhadraya K, Reddy YP, Reddy CS, Lokesh T. Analytical quality by design approach in RP-HPLC method development for the assay of Etofenamate in dosage forms. Indian J Pharm Sci. 2015;77(6):751-7.

Petkovska R, Cornett C, Dimitrovska A. Development and validation of rapid resolution RP-HPLC method for simultaneous determination of atorvastatin and related compounds by use of chemometrics. Anal Lett. 2008;41(6):992-1009.
Pradipbhai DK, Deepak N, Srinivas R, Gananadhamu S. Application of experimental design and response surface technique for selecting the optimum RP-HPLC conditions for the determination of moxifloxacin HCL and ketorolac tromethamine in eye drops. J Saudi Chem Soc. 2017;21(suppl 1):373-82.

Ramesh J, Senthil Kumar N. A validated high performance liquid chromatography method for the determination of saxagliptin and metformin in bulk and pharmaceutical dosage form, a stability indicating study. IOSR J Pharma Biol Sci. 2016;11(6):92-100.

Scheeren LE, Marcolino AIP, Adams AIH, Rolim CMB. Stability indicating RP-LC-PDA method for the quantitative analysis of saxagliptin in pharmaceutical dosage form. Braz $\mathrm{J}$ Pharm Sci. 2015;51(2):461-6.

Subrata S, Vipul PP. Method development and validation of dapagliflozine drug in bulk and tablet dosage form by RP-HPLC. Int J Pharma Res Health Sci. 2017;5(4):1755-9.

Thakur D, Kaur A, Sharma S. Application of QbD based approach in method development of RP-HPLC for simultaneous estimation of antidiabetic drugs in pharmaceutical dosage forms. J Pharm Invest. 2017;47(3):229-39.

Vinutha K, Chowdary KPR, Prasad SVUM. Development of a new stability indicating RP-HPLC method for simultaneous estimation of saxagliptine and dapagliflozin and its validation as per ICH guidelines. Indo Am J Pharm Sci. 2017; 4(9):2920-32.

Yadav NK, Raghuvanshi A, Sharma G, Beg S, Katare OP, Nanda S. QbD-based development and validation of a stability-indicating HPLC method for estimating ketoprofen in bulk and proniosomal vesicular system. J Chromatogr Sci. 2016;54(3):377-89.

Received for publication on $07^{\text {th }}$ March 2018 Accepted for publication on $27^{\text {th }}$ June 2018 